\title{
Minor Contribution of Cardiac Progenitor Cells in Neonatal Heart Regeneration
}

\author{
Wataru Kimura, Shalini A. Muralidhar, and SuWannee Thet
}

\section{Keywords}

Heart regeneration $\bullet$ Cardiomyocyte proliferation $\bullet$ Cardiac progenitor cells

The adult mammalian heart is incapable of regeneration after injury, as shown by the limited amount of cardiomyocyte proliferation and poor neovascularization. We recently showed that neonatal mice have a remarkable ability to regenerate damaged heart after apical resection or myocardial infarction (MI), which includes complete reconstruction of myocardial wall with vascular network [2, 3]. Although lineage tracing showed that the main source of newly formed cardiomyocyte is preexisting cardiomyocytes, it is still possible that there is a minor contribution of other types of cells to the cardiomyocyte. In addition, lineage origin of the newly formed vasculature during postnatal cardiac maturation and neonatal heart regeneration remains unclear (Fig. 50.1).

In order to trace the lineage of non-myocyte-derived cells during neonatal heart regeneration, we utilized Rosa26-tdTomato reporter mouse line crossed with capsulin-merCremer line in which epicardial cells and interstitial fibroblasts are labeled specifically and irreversibly after induction with tamoxifen [1]. At postnatal day 0 (P0), Cre was activated by intraperitoneal injection of tamoxifen, and then MI was induced 2 days later (P2). Subsequently the hearts were harvested at 21 days after MI and tdTomato expression was examined. tdTomato + cells were detected in the epicardium, interstitial fibroblasts, vascular endothelium, and smooth muscle in the regenerated heart. Remarkably, we could detect a very small

W. Kimura $(\varangle) \cdot$ S.A. Muralidhar $\bullet$ S. Thet

Departments of Internal Medicine, The University of Texas Southwestern Medical Center, Dallas, TX 75390, USA

e-mail: Wataru.Kimura@UTSouthwestern.edu; waterkimura@gmail.com

T. Nakanishi et al. (eds.), Etiology and Morphogenesis of Congenital Heart Disease, DOI 10.1007/978-4-431-54628-3_50 


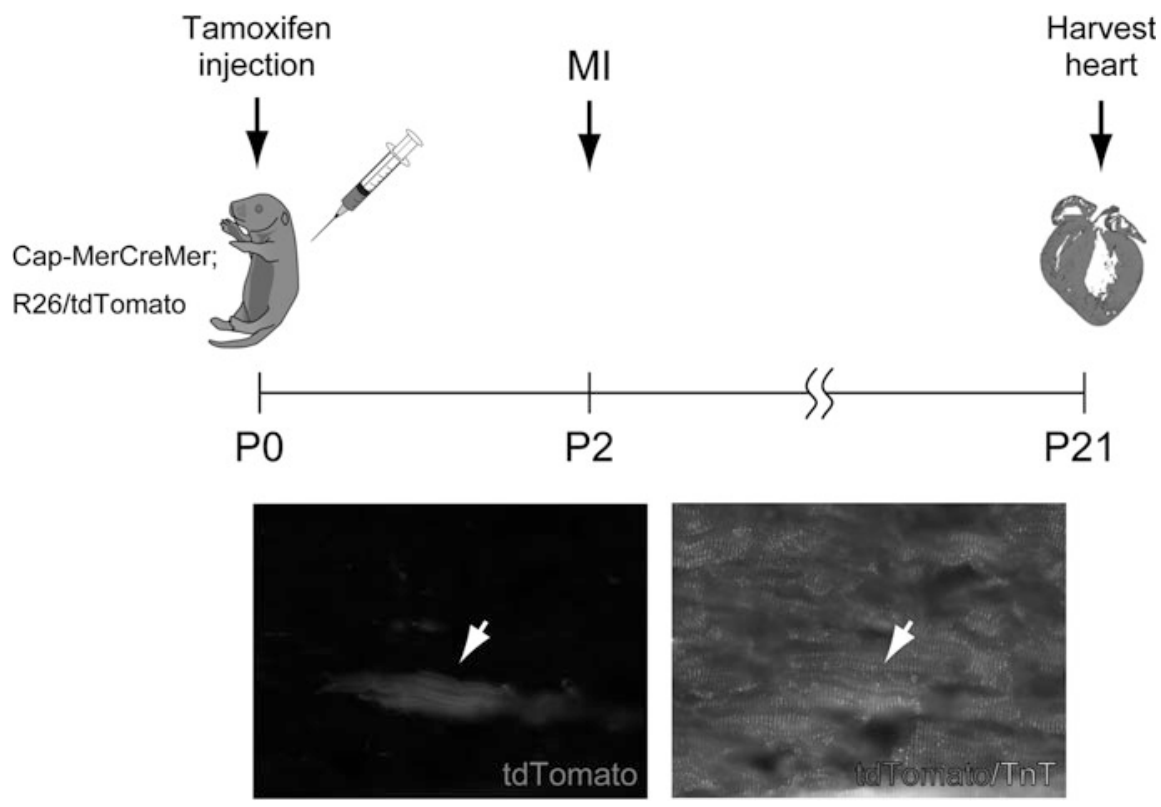

Fig. 50.1 Capsulin-positive cardiac progenitor cells contribute to myocardial lineages during neonatal heart regeneration. Schematics show experimental outline for genetic fate mapping after neonatal MI. Lower panels show immunofluorescence on section of 21 days post-MI heart. tdTomato-labeled cells are found in cardiac troponin $\mathrm{T}(\mathrm{TnT})$-positive cardiomyocytes

population (1-2 cells/section) of tdTomato+ cardiomyocyte in the regenerated neonatal heart. No tdTomato+ cardiomyocyte was detected at P21 without inducing MI. These results strongly suggest that capsulin-positive cardiac progenitor cells play important roles during neonatal heart regeneration, primarily in neovasculogenesis by contributing directly to the endothelial/smooth muscle progenitor cells and to a much lesser extent rare myocytes.

Open Access This chapter is distributed under the terms of the Creative Commons AttributionNoncommercial 2.5 License (http://creativecommons.org/licenses/by-nc/2.5/) which permits any noncommercial use, distribution, and reproduction in any medium, provided the original author(s) and source are credited.

The images or other third party material in this chapter are included in the work's Creative Commons license, unless indicated otherwise in the credit line; if such material is not included in the work's Creative Commons license and the respective action is not permitted by statutory regulation, users will need to obtain permission from the license holder to duplicate, adapt or reproduce the material.

\section{References}

1. Acharya A, Baek ST, Banfi S, Eskiocak B, Tallquist MD. Efficient inducible Cre-mediated recombination in Tcf21 cell lineages in the heart and kidney. Genesis. 2011;49:870-7. 
2. Porrello ER, Mahmoud AI, Simpson E, Hill JA, Richardson JA, Olson EN, et al. Transient regenerative potential of the neonatal mouse heart. Science. 2011;331:1078-80.

3. Porrello ER, Mahmoud AI, Simpson E, Johnson BA, Grinsfelder D, Canseco D, et al. Regulation of neonatal and adult mammalian heart regeneration by the miR-15 family. Proc Natl Acad Sci U S A. 2013;110:187-92. 